\title{
Diet and physical activity in people with intermediate cardiovascular risk and their relationship with the health-related quality of life: results from the MARK study
}

\author{
Natalia Sanchez-Aguadero ${ }^{\text {* }}$, Rosario Alonso-Dominguez ${ }^{1}$ Luis Garcia-Ortiz “2, Cristina Agudo-Conde, \\ Carmela Rodriguez-Martin ${ }^{1}$, Angela de Cabo-Laso ${ }^{1}$, Benigna Sanchez-Salgado ${ }^{1}$, Rafel Ramos ${ }^{3}$, \\ Jose A. Maderuelo-Fernandez ', Manuel A. Gomez-Marcos ${ }^{1,4}$, Jose I. Recio-Rodriguez ${ }^{1,5}$ and MARK Group
}

\begin{abstract}
Background: To analyze the interplay between diet, physical activity and health-related quality of life in a Spanish randomly selected sample of individuals attended in general practitioners offices with intermediate cardiovascular risk.

Methods: This study analyzed 314 subjects, aged 35-74 years (50.6\% women), from the MARK study, conducted in Spain. Health related quality of life was measured by the SF-12 questionnaire. The assessment of the lifestyles included the diet quality index, the adherence to the Mediterranean diet and the leisure time physical activity practice.

Results: The highest values of health related quality of life were obtained in the area of vitality $(51.05 \pm 11.13)$, while the lowest were found in the general health $(39.89 \pm 8.85)$. In the multiple linear regression analysis, after adjustment for age, gender and other confounders, for each point of increase in the Mediterranean diet adherence score, there was an increase of 1.177 points in the mental component value $(p<0.01)$. Similarly, for each point of increase in the Diet Quality Index Score, there was an increase in the mental component of $0.553(p<0.05)$. Likewise, the physical activity was positively associated with the physical function and vitality ( $\beta=0.090$ and $0.087,(p<0.01$ and $p<0.05)$, respectively).
\end{abstract}

Conclusions: In people with intermediate cardiovascular risk, better food habits and greater adherence to the Mediterranean diet are associated with higher scores on the mental component of quality of life. Likewise, increased physical activity is related with positive scores on the physical function.

Keywords: Health-related quality of life, Life style, Food habits, Exercise

\section{Background}

Self-reporting of health outcomes have increasing relevance to research, clinical practice and health planning $[1,2]$. Analysis of quality of life provides complementary information to traditional health indicators based on morbidity and mortality [3] and it is a valid measurement for self-perceived mental and physical health

\footnotetext{
* Correspondence: natalia.san.ag@gmail.com

'Primary Care Research Unit, The Alamedilla Health Center, Castilla and León Health Service (SACYL), Biomedical Research Institute of Salamanca (IBSAL), Spanish Network for Preventive Activities and Health Promotion (redIAPP), 37003 Salamanca, Spain

Full list of author information is available at the end of the article
}

status that is closely associated with cardiovascular disease and all-cause mortality $[4,5]$. One of the most used instruments worldwide to measure the health related quality of life (HRQL) is the SF-36 questionnaire or its shorter version SF-12 that reduces the administration workload [3, 4].

Self-perceived health status has been previously associated with diet. Poor diet quality, characterized by low consumption of particular healthy foods or nutrients has been associated with low mental and physical health [5-9]. Furthermore, evidence from dietary intervention studies indicates an improvement of quality of life through healthy diets $[10,11]$. It has been argued that the social 
and cultural aspects related to the Mediterranean diet may provide additional health benefits [12]. The PREDIMED study showed in a follow-up period of 4.8 years, that an energy-unrestricted Mediterranean diet which includes consumption of extra-virgin olive oil or nuts resulted in an absolute risk reduction of approximately 3 major cardiovascular events per 1000 person-year, for a relative risk reduction of approximately $30 \%$. These results support the benefits of the Mediterranean diet for cardiovascular risk reduction [13].

Currently, physical inactivity is a major public health problem [14]. Exercise reduces mortality and lowers the risk of developing physical and mental chronic diseases [15]. Studies in the general population [16-19] have found a positive association between physical activity, vitality and mental health. This improves the overall quality of life $[20,21]$. Similar results were found in special populations such as the elderly or the obese [22, 23].

The subgroup of patients with intermediate cardiovascular risk is the group in which the highest number of cardiovascular events occur [24], and it is known the association of these with a worse HRQL [25]. The European Guidelines on cardiovascular disease prevention in clinical practice highlights the importance in those subjects of promoting healthy lifestyle behaviour by tackling unhealthy lifestyles (e.g. poor-quality diet, physical inactivity, smoking) and by optimising risk factors $[26,27]$. Some studies have analyzed the relationship between quality of life, exercise and Mediterranean diet in healthy subjects and individuals with various pathologies but few have focused their research on individuals with intermediate cardiovascular risk. Therefore, the purpose of this study is to analyze the interplay between diet, physical activity and health related quality of life in a Spanish randomly selected sample of individuals attended in general practitioners offices with intermediate cardiovascular risk.

\section{Methods \\ Design}

The MARK study [28] is a longitudinal study to evaluate if ankle-brachial index (ABI), measures of arterial stiffness (CAVI), postprandial glucose, glycosylated hemoglobin, self-measured blood pressure and the presence of comorbidities are independently associated with the incidence of vascular events and whether they can improve the predictive capacity of current risk equations in the intermediate risk population. The current study refers to the baseline visit. The second step will be 5- and 10-years follow up to evaluate cardiovascular morbidity and mortality.

\section{Study population}

The study population comprised 500 subjects recruited in Salamanca, aged 35-74 years, with intermediate cardiovascular risk, defined as coronary risk $5-15 \%$ at
10 years according to the adaptation of the Framingham risk equation (REGICOR) [29], risk of cardiovascular mortality among $1-5 \%$ to 10 years according to the SCORE equation [30] or moderate risk according to the 2007 European Society of Hypertension guidelines for the management of arterial hypertension [31]. Terminal illness, institutionalization at the time of the appointment or personal history of atherosclerotic disease was excluded. Sample selection was performed by random sampling from the individuals attended for general practitioners at a health center that matched the inclusion criteria. The recruitment and data collection were carried out between July 2011 and June 2013. The current study analyzed 314 of these participants that were assessed for HRQL.

\section{Sample size calculation}

The sample size was estimated to recognize as statistically significant a difference greater than or equal to 3.75 units on the SF-12 score between sedentary and active subjects (ratio 3:1). Accepting an alpha risk of 0.05 and a beta risk of 0.2 in a two-sided test, 78 subjects are necessary in first group and 234 in the second one. The common standard deviation is assumed to be 10 . We anticipated a drop-out rate of 3.5\%.

\section{Measurements \\ Assesment of the usual diet and the adherence to the Mediterranean diet}

The usual diet was evaluated with the diet quality index (DQI) [32], a validated questionnaire about the frequency of consumption of 18 food groups divided into three categories. The first one included daily food consumption; less than, equal to or greater than 1 serving/ day was scored with 1,2 and 3 points, respectively; except for alcohol, in which case 3 points were assigned to the daily consumption of 1 alcoholic beverage and 1 point to an intake greater or lower than 1 per day. The second category, relating to weekly food consumption considered detrimental, was valuated with 2 points when the consumption was between 4 and 6 servings/week and 1 and 3 points when the intake was lower and upper, respectively. The third category included foods considered beneficial whose consumption between 2 and 3 times per week got 2 points, while the highest and lowest were scored with 3 and 1 point, respectively. Total score had a range from 18 to 54 points, with higher scores associated to a better diet quality. Adherence to the Mediterranean diet was collected with a short questionnaire previously validated, which provides 9 items relating to compliance with various aspects of the Mediterranean diet such as the consumption of olive oil, vegetables, fruit, nuts or white meat. Scores equal to 
or greater than 5 points are considered good compliance of the Mediterranean diet [33].

\section{Assesment of the regular physical activity}

Leisure time physical activity (LTPA) practice was collected with the short version of the Minnesota LTPA Questionnaire validated for Spanish men and women $[34,35]$. The questionnaire was administered by trained interviewers colleting detailed information about physical activity (PA) during the preceding year, the number of times this activity was performed and the average duration of each activity on each occasion. Each PA has an intensity code based on the ratio between the metabolic rate during PA practice and the basal metabolic rate (MET). We assumed that 1 MET approximately corresponds to $1 \mathrm{kcal} / \mathrm{min}$ of energy expenditure. Therefore, we can calculate the total energy expenditure in leisure time of PA in kilocalories per week. Consumption of MET-min was estimated at week by multiplying the MET in physical activity for their duration (in minutes) and cumulative frequency in the month prior to the interview. We classified people according to energy expenditure in leisure time for 14 days in the following categories [36]: Very active: energy expenditure above 5000 METs-min/14 days; Active: energy expenditure between 3000 and 4999 METs-min/14 days; Moderately active: energy expenditure between 1250 and 2999 METs-min/14 days and Sedentary: less than 1250 METs$\mathrm{min} / 14$ days energy expenditure.

\section{Health related quality of life (HRQL)}

HRQL was assessed with the Spanish version of the SF12 v.2, which has been validated [3, 4]. The SF-12 is a shorter version of the SF-36 questionnaire [37], and includes 12 items, with 3 to 5 response categories on a Likert scale. The SF-12 questionnaire is self-administered and was developed to measure eight dimensions of HRQL: Physical Functioning, Role Physical, Body Pain, General Health, Vitality, Role Emotional, Social Functioning and Mental Health. These eight dimensions can be aggregated into two summary measures: a physical component summary (PCS-12) and a mental component summary (MCS12). To estimate summary components of SF-12 (PCS-12 and MCS-12), we calculated the algebraic sum of the standardized scores of eight dimensions (z scores) weighted by weights. Physical and Mental Health Composite Scores (PCS-12 \& MCS-12) are computed using the scores of the twelve questions and range from 0 to 100 , where a zero score indicates the lowest level of health measured by the scales and 100 indicates the highest level of health [38]. The values are standardized to a US norm with a mean of 50 and a standard deviation of 10 . Thus, the SF-12 summaries compare the scores for each study participant against the mean score in the population. A higher score in the PCS-12 or the MCS-12 corresponds to better health status. The two standardized summary scores provide a concise approximation of the physical and mental components of HRQL [38]. More details and a brief description of the components of the SF-12 questionnaire can be seen in Additional file 1: Table S1.

\section{Definition of cardiovascular risk factors}

Hypertension was defined as having one or more of the following conditions: physician-diagnosed hypertension, systolic blood pressure $(\mathrm{BP}) \geq 140 \mathrm{mmHg}$, diastolic $\mathrm{BP} \geq$ $90 \mathrm{mmHg}$ and use of antihypertensive agents. Dyslipidemia was defined as having one or more of the following conditions: physician-diagnosed dyslipidemia, total cholesterol $\geq 250 \mathrm{mg} / \mathrm{dl}$ and use of lipid-lowering agents. Type 2 diabetes was defined as having one or more of the following conditions: physician-diagnosed type 2 diabetes, fasting plasma glucose (FPG) $\geq 126 \mathrm{mg} / \mathrm{dl}$, $\mathrm{HbA} 1 \mathrm{c} \geq 6.5 \%$ and use of oral hypoglycemic agents. In relation to lifestyle habits, we classified the participants as non-smokers or current smokers and considered alcohol risk consumption when the intake was $\geq 290 \mathrm{~g} /$ week in males or $\geq 180 \mathrm{~g} /$ week in females.

\section{Comorbidity study}

The Charlson Comorbidity Index, which contains 19 comorbidity categories, was calculated. Each index category has an associated weight, taken from the original Charlson's document [39], which is based on the adjusted mortality risk per year. The overall comorbidity score reflects the greater cumulative probability of mortality per year. The higher the score the more severe the comorbidity burden is.

\section{Other variables}

Clinical blood pressure (BP) determination involved three measurements of systolic blood pressure (SBP) and diastolic blood pressure (DBP), made with a validated sphygmomanometer (OMRON Model M10-IT) on the dominant arm of participants in the seated position after at least 5 min of rest with a cuff of appropriate size as determined by measurement of the upper arm circumference, using the average of the last two and following the recommendations of the European Society of Hypertension [40]. Body weight was determined on two occasions, with the subject wearing light clothing and no shoes, using a homologated electronic balance (Seca 770) properly calibrated (precision $\pm 0.1 \mathrm{~kg}$ ). Height was measured with subject standing barefoot, recording the average of two readings rounded to the nearest centimeter, using a portable system (Seca 222). Body mass index (BMI) was calculated as the weight $(\mathrm{kg})$ divided by height squared $\left(\mathrm{m}^{2}\right)$. Obesity was defined at values $\geq 30 \mathrm{~kg} / \mathrm{m}^{2}$. Blood and urine tests were performed to 
evaluate lipids, glucose and kidney function to assess vascular risk. Other variables included sociodemographic variables and medical treatments.

\section{Statistical analysis}

The results are expressed as mean \pm standard deviation in quantitative variables or by the frequency distribution in the case of qualitative variables. Normality was assessed using the Kolmogorov-Smirnov test. The Chi-square test analyzed the association between independent qualitative variables. We used the Student's $t$ test for independent samples or Mann-Whitney test to compare the average of two groups. The relationship between quantitative variables were analyzed using the Pearson correlation coefficient. We performed three multiple linear regression analyses using the Multivariate General Linear Model (GLM), including as independent variables the mediterranean diet adherence, DQI and METS-min/week/100 (to facilitate the intrepretation). The eight SF-12 dimensions and standardized physical and mental component were the dependent variables. We performed a first model unadjusted and a second model adjusted for age, gender, hypertension, dyslipidemia and Charlson Comorbidity Index. For bilateral hypothesis contrasts, an alpha risk of 0.05 was set as the limit of statistical significance using SPSS v.21.0.

\section{Results}

The study population consists of 314 participants with a mean age of $61.1 \pm 8.4$ years ( $50.6 \%$ women). The main risk factors included $86.6 \%$ with dyslipidemia, $75.8 \%$ with hypertension, $26.4 \%$ with obesity and $24.2 \%$ with Type 2 diabetes mellitus. With respect to lifestyle, 167 (53.2\%) followed the Mediterranean diet, 78 (24.8\%) were sedentary, $68(21.7 \%)$ were current smokers at the time of interview, and 21 (6.7\%) were at a high risk level of alcohol consumption. There were gender differences for physical activity and alcohol consumption, in favor of men. All characteristics of the study population are presented in Table 1.

Table 1 Clinical characteristics and lifestyles of the study population

\begin{tabular}{|c|c|c|c|c|c|c|c|}
\hline & \multicolumn{2}{|l|}{$\begin{array}{l}\text { Global } \\
n=314\end{array}$} & \multicolumn{2}{|l|}{$\begin{array}{l}\text { Men } \\
n=155(49,4 \%)\end{array}$} & \multicolumn{2}{|l|}{$\begin{array}{l}\text { Women } \\
n=159(50,6 \%)\end{array}$} & \multirow[b]{2}{*}{$p$ value } \\
\hline & Mean or number & SD or $\%$ & Mean or number & SD or $\%$ & Mean or number & SD or $\%$ & \\
\hline Age (years) & 61.1 & 8.4 & 60.0 & 8.9 & 62.2 & 7.9 & 0.019 \\
\hline Hypertension (n, \%) & 238 & 75.8 & 122 & 78.7 & 116 & 73 & 0.239 \\
\hline Type 2 Diabetes Mellitus (n, \%) & 76 & 24.2 & 44 & 28.4 & 32 & 20.1 & 0.113 \\
\hline Dyslipidemia (n, \%) & 272 & 86.6 & 132 & 85.2 & 140 & 88.1 & 0.509 \\
\hline Obesity (n, \%) & 83 & 26.4 & 39 & 25.2 & 44 & 27.7 & 0.701 \\
\hline Body mass index $\left(\mathrm{Kg} / \mathrm{m}^{2}\right)$ & 28.1 & 4.3 & 28.2 & 3.6 & 28.0 & 4.9 & 0.721 \\
\hline \multicolumn{8}{|l|}{ Diet } \\
\hline Adherence to the Mediterranean diet $(n, \%)$ & 167 & 53.2 & 75 & 48.4 & 92 & 57.9 & 0.113 \\
\hline Mediterranean diet (total score) & 5.5 & 1.5 & 5.4 & 1.5 & 5.6 & 1.5 & 0.243 \\
\hline Diet Quality Index (total score) & 31.3 & 2.7 & 31.3 & 2.8 & 31.4 & 2.6 & 0.728 \\
\hline \multicolumn{8}{|l|}{ Physical activity } \\
\hline METS-min/week & 1773 & 1703 & 2211 & 2086 & 1346 & 1062 & $<0.001$ \\
\hline \multicolumn{8}{|l|}{ Physical activity classification } \\
\hline Sedentary (n, \%) & 78 & 24.8 & 31 & 20.0 & 47 & 29.6 & $<0.001$ \\
\hline Moderately active (n, \%) & 90 & 28.7 & 41 & 26.5 & 49 & 30.8 & \\
\hline Active $(n, \%)$ & 71 & 22.6 & 30 & 19.4 & 41 & 25.8 & \\
\hline Very active $(n, \%)$ & 75 & 23.9 & 53 & 34.2 & 22 & 13.8 & \\
\hline \multicolumn{8}{|l|}{ Tobacco } \\
\hline Smokers (n, \%) & 68 & 21.7 & 38 & 24.5 & 30 & 18.9 & 0.273 \\
\hline \multicolumn{8}{|l|}{ Alcohol } \\
\hline Grames/week & 73.1 & 109.9 & 116.4 & 134.9 & 30.9 & 50.7 & $<0.001$ \\
\hline Risk consumption ( $\mathrm{n}, \%)$ & 21 & 6.7 & 17 & 11.0 & 4 & 2.5 & $<0.001$ \\
\hline \multicolumn{8}{|l|}{ Comorbidities } \\
\hline Charlson Comorbidity Index & 2.5 & 0.8 & 2.5 & 0.8 & 2.5 & 0.9 & 0.376 \\
\hline
\end{tabular}


Table 2 describes the mean scores in the quality of life questionnaire (SF-12). The highest values were obtained in the area of vitality $(51.05 \pm 11.13)$, while the lowest were found in the general health $(39.89 \pm 8.85)$. For all items, self-perception was greater in men $(p<0.05)$ except for the general health and vitality.

The METs-min/week were directly related to the physical and mental component $(r=0.141, p<0.05)$ $(r=0.112, p<0.05)$, respectively. This was more significant with physical function $(r=0.252, p<0.01)$. It was also associated with bodily pain, vitality, as well as emotional and mental health $(p<0.05$, all). The Mediterranean Diet (total score) was related to the mental component $(r=0.164, p<0.01)$ as well as social functioning $(r=0.172, p<0.01)$ and vitality $(r=0.122, p<0.05)$. Moreover, the index of diet quality (DQI) was directly related to the mental component $(r=0.127, p<0.05)$ and mental health $(r=0.121, p<0.05)$ (Table 3).

In the multiple linear regression analysis (Table 4), after adjusting for age, gender, hypertension, dyslipidemia and Charlson Comorbidity Index, we found a 1.177 point increase in the mental component for each increase of 1 point in the Mediterranean diet adherence score $(p<0.01)$. Vitality and Social Functioning also kept these associations after the adjustment $(\beta=0.958$ and 0.990, $(p<0.05$ and $p<0.01)$, respectively). Furthermore, Mediterranean diet adherence score was inversely associated with Role Physical, regardless of the adjustment variables considered $(\beta=-0.694,(p<0.05))$. Similarly, for each point of increase in the Diet Quality Index Score, there would be an increase in the mental health of 0.553 and in the mental component of $0.553(p<0.01$ and $p<0.05$, respectively). In contrast, after the adjustment, the physical activity was associated with the physical function and vitality $(\beta=0.090$ and $0.087,(p<0.01$ and $p<0.05)$, respectively).

\section{Discussion}

Food habits are related to the mental component of quality of life while physical activity is related to the physical function in a large sample of subjects with intermediate cardiovascular risk. Better food habits-characterized by greater adherence to the Mediterranean diet and a higher score on the diet quality index (DQI) - had the best scores on the mental component, vitality and social function. Likewise, increased physical activity as evaluated with the short Minnesota questionnaire is related to better physical function. To our knowledge, these are the first results that the quality of life is associated with lifestyles related to diet and physical exercise in a sample of adults with intermediate cardiovascular risk. This population has a privileged position to be the target in changing lifestyles that aim at preventing cardiovascular disease and improving quality of life. This relationship (between lifestyles and HRQL) has been shown to exist in other populations but not in subjects with an intermediate CVR [41-43].

Our data indicate that the perceived quality of life could be influenced by physical activity. We found a direct association that occurs for physical and mental components and for the majority of dimensions. However, after adjustment for confounders, only the physical function and vitality maintained statistical significance. These findings are consistent with those published by Kovacs et al. [17] in elderly women. After participating in an adapted physical activity program, there was a significant increase in the dimensions of physical function and vitality. Similarly, the comprehensive review of Vagetti et al. [44] indicated a positive association between physical activity and quality of life in the elderly that was consistently associated with functional ability and vitality, among other domains. A cross-sectional study of adults with obesity conducted by Jepsen et al. [23] prior to a lifestyle intervention showed a significant

Table 2 Health-related quality of life (SF12)

\begin{tabular}{|c|c|c|c|c|c|c|c|}
\hline & \multicolumn{2}{|c|}{$\begin{array}{l}\text { Global } \\
n=314\end{array}$} & \multicolumn{2}{|c|}{$\begin{array}{l}\text { Men } \\
n=155(49,4 \%)\end{array}$} & \multicolumn{2}{|c|}{$\begin{array}{l}\text { Women } \\
n=159(50,6 \%)\end{array}$} & \multirow[b]{2}{*}{$p$ value } \\
\hline & Mean & SD & Mean & SD & Mean & SD & \\
\hline Physical component & 48.36 & 9.29 & 50.05 & 7.55 & 46.71 & 10.48 & 0.001 \\
\hline Mental component & 49.47 & 10.48 & 51.36 & 9.74 & 47.64 & 10.88 & 0.002 \\
\hline Physical function & 50.69 & 9.04 & 52.53 & 7.90 & 48.90 & 9.72 & $<0.001$ \\
\hline Physical role & 50.92 & 9.20 & 52.59 & 8.19 & 49.29 & 9.85 & 0.001 \\
\hline Bodily pain & 49.84 & 11.65 & 53.23 & 9.27 & 46.54 & 12.77 & $<0.001$ \\
\hline General health & 39.89 & 8.85 & 40.63 & 8.51 & 39.16 & 9.13 & 0.142 \\
\hline Vitality & 51.05 & 11.13 & 52.16 & 11.18 & 49.96 & 11.01 & 0.080 \\
\hline Social functioning & 49.87 & 9.75 & 51.61 & 8.79 & 48.18 & 10.36 & 0.002 \\
\hline Emotional role & 48.88 & 9.70 & 50.66 & 9.06 & 47.14 & 10.00 & 0.001 \\
\hline Mental health & 49.68 & 10.45 & 52.46 & 10.03 & 46.98 & 10.18 & $<0.001$ \\
\hline
\end{tabular}


Table 3 Bivariate correlations between health related quality of life and lifestyles

\begin{tabular}{|c|c|c|c|c|c|c|c|c|c|c|}
\hline & $\begin{array}{l}\text { Physical } \\
\text { component }\end{array}$ & $\begin{array}{l}\text { Mental } \\
\text { component }\end{array}$ & $\begin{array}{l}\text { Physical } \\
\text { function }\end{array}$ & $\begin{array}{l}\text { Physical } \\
\text { role }\end{array}$ & $\begin{array}{l}\text { Bodily } \\
\text { pain }\end{array}$ & $\begin{array}{l}\text { General } \\
\text { health }\end{array}$ & Vitality & $\begin{array}{l}\text { Social } \\
\text { functioning }\end{array}$ & $\begin{array}{l}\text { Emotional } \\
\text { role }\end{array}$ & $\begin{array}{l}\text { Mental } \\
\text { health }\end{array}$ \\
\hline Standardized METS ${ }^{a}$ & $0.141^{*}$ & $0.112^{*}$ & $0.252^{* *}$ & 0.107 & $0.122^{*}$ & 0.104 & $0.117^{*}$ & 0.075 & $0.128^{*}$ & $0.141^{*}$ \\
\hline Mediterranean diet & -0.022 & $0.164^{* *}$ & -0.023 & -0.083 & -0.032 & 0.091 & $0.122^{*}$ & $0.172^{* *}$ & 0.087 & 0.083 \\
\hline Diet quality index & -0.056 & $0.127^{*}$ & 0.004 & -0.023 & -0.047 & 0.051 & 0.014 & 0.078 & 0.073 & $0.121^{*}$ \\
\hline
\end{tabular}

${ }^{a} M E T$ basal metabolic rate

${ }^{*} p<0.05,{ }^{* *} p<0.01$

Table 4 Multiple regression analysis of lifestyles health-related quality of life

\begin{tabular}{|c|c|c|c|c|c|c|c|c|c|}
\hline \multirow[b]{2}{*}{ Independent variable } & \multirow[b]{2}{*}{ Dependent variable } & \multicolumn{4}{|c|}{ Without adjustment } & \multicolumn{4}{|c|}{$\begin{array}{l}\text { Adjusted for age, sex, hypertension, dyslipidemia and Charlson } \\
\text { Comorbidity Index }\end{array}$} \\
\hline & & $\beta$ & $95 \% \mathrm{Cl}^{\mathrm{a}}$ & & $p$ value & $\beta$ & $95 \% \mathrm{Cl}^{\mathrm{a}}$ & & $p$ value \\
\hline \multirow[t]{10}{*}{ Mediterranean diet } & Physical component & -0.593 & -1.285 & 0.099 & 0.093 & $-0,582$ & -1.273 & 0.109 & 0.098 \\
\hline & Mental component & 1.209 & 0.437 & 1.982 & 0.002 & 1,177 & 0.415 & 1.939 & 0.003 \\
\hline & Physical function & -0.298 & -0.974 & 0.378 & 0.386 & -0.229 & -0.900 & 0.442 & 0.502 \\
\hline & Role physical & -0.637 & -1.322 & 0.048 & 0.068 & -0.694 & -1.372 & -0.017 & 0.045 \\
\hline & Bodily pain & -0.508 & -1.378 & 0.363 & 0.252 & -0.499 & -1.339 & 0.341 & 0.243 \\
\hline & General health & 0.558 & -0.102 & 1.217 & 0.097 & 0.500 & -0.163 & 1.163 & 0.139 \\
\hline & Vitality & 0.898 & 0.071 & 1.725 & 0.033 & 0.958 & 0.132 & 1.785 & 0.023 \\
\hline & Social functioning & 1.037 & 0.316 & 1.758 & 0.005 & 0.990 & 0.278 & 1.702 & 0.007 \\
\hline & Role emotional & 0.540 & -0.183 & 1.263 & 0.143 & 0.527 & -0.192 & 1.245 & 0.150 \\
\hline & Mental health & 0.612 & -0.168 & 1.391 & 0.124 & 0.572 & -0.179 & 1.324 & 0.135 \\
\hline \multirow[t]{10}{*}{$\mathrm{DQ}^{\mathrm{b}}$} & Physical component & -0.175 & -0.556 & 0.206 & 0.366 & -0.223 & -0.607 & 0.161 & 0.254 \\
\hline & Mental component & 0.583 & 0.158 & 1.008 & 0.007 & 0.553 & 0.129 & 0.977 & 0.011 \\
\hline & Physical function & -0.017 & -0.388 & 0.354 & 0.929 & -0.042 & -0.414 & 0.330 & 0.824 \\
\hline & Role physical & 0.034 & -0.343 & 0.412 & 0.858 & -0.055 & -0.433 & 0.323 & 0.774 \\
\hline & Bodily pain & -0.161 & -0.638 & 0.317 & 0.508 & -0.217 & -0.683 & 0.249 & 0.360 \\
\hline & General health & 0.275 & -0.086 & 0.637 & 0.135 & 0.242 & -0.126 & 0.609 & 0.197 \\
\hline & Vitality & 0.159 & -0.297 & 0.615 & 0.493 & 0.186 & -0.275 & 0.648 & 0.428 \\
\hline & Social functioning & 0.339 & -0.059 & 0.737 & 0.095 & 0.281 & -0.117 & 0.680 & 0.165 \\
\hline & Role emotional & 0.342 & -0.053 & 0.738 & 0.090 & 0.303 & -0.095 & 0.702 & 0.135 \\
\hline & Mental health & 0.606 & 0.183 & 1.030 & 0.005 & 0.553 & 0.139 & 0.966 & 0.009 \\
\hline \multirow[t]{10}{*}{ METS'-min/week } & Physical component & 0.032 & 0.002 & 0.062 & 0.038 & 0.039 & -0.025 & 0.103 & 0.233 \\
\hline & Mental component & 0.029 & -0.005 & 0.063 & 0.099 & 0.018 & -0.053 & 0.089 & 0.623 \\
\hline & Physical function & 0.054 & 0.025 & 0.083 & $<0.001$ & 0.090 & 0.029 & 0.151 & 0.004 \\
\hline & Role physical & 0.019 & -0.011 & 0.049 & 0.212 & 0.005 & -0.068 & 0.058 & 0.870 \\
\hline & Bodily pain & 0.030 & -0.008 & 0.068 & 0.122 & -0.003 & -0.080 & 0.075 & 0.949 \\
\hline & General health & 0.024 & -0.005 & 0.053 & 0.106 & 0.039 & -0.022 & 0.100 & 0.212 \\
\hline & Vitality & 0.047 & 0.011 & 0.083 & 0.011 & 0.087 & 0.010 & 0.163 & 0.026 \\
\hline & Social functioning & 0.015 & -0.017 & 0.047 & 0.354 & -0.009 & -0.075 & 0.058 & 0.793 \\
\hline & Role emotional & 0.030 & -0.002 & 0.062 & 0.063 & 0.028 & -0.038 & 0.094 & 0.408 \\
\hline & Mental health & 0.038 & 0.004 & 0.072 & 0.027 & 0.017 & -0.053 & 0.086 & 0.636 \\
\hline
\end{tabular}

${ }^{a} \mathrm{Cl}$ confidence interval, ${ }^{\mathrm{b}} \mathrm{DQ}$ diet quality index, ${ }^{\mathrm{C}} \mathrm{MET}$ basal metabolic rate Bold data reflect $p$ values $<0.05$ 
association with general health. In contrast, a randomized controlled clinical trial of inactive persons [16] with a program to promote physical activity as an intervention, found no statistically significant changes between the experimental and control group in regard to the quality of life related to health. Other authors have evaluated the quality of life with specific tools for their study population (elderly, obese and patients with cystic fibrosis) $[22,45,46]$. Similar to our work, they found that physical activity is directly associated with quality of life. Our results would support the idea that physical activity has implications on quality of life related to health to the extent that it might promote individual autonomy through positive changes in dimensions such as the physical functioning.

Our results support the findings of other studies [42] suggesting a beneficial association of DM with quality of life. However, we include a novelty little studied, the relationship between the quality of food, as measured by the DQI, with the quality of life. The DQI was created to rapidly capture quality of diet based on food intake. Diet quality indexes address the diet's complexity and are calculated by a combination of foods and/or nutrients with a total score depicting overall diet quality [47]. In our study population, greater adherence to the Mediterranean diet was associated with higher scores on the SF-12 mental component, social functioning and vitality. Similarly, the diet quality index (DQI) showed an association with the mental component. Adopting a MD in adulthood reduces chronic disease burden and all-cause mortality [48]. Recent studies show that better adherence to the Mediterranean diet is associated with lower cardiovascular disease [13], lower risk of metabolic syndrome [49], better cognitive performance [50] and has a favourable role on the prevention of colorectal cancer [51]. These data are consistent with those published by Henriquez Sánchez et al., [52]. In a cohort study of Spanish university graduates, a positive association was observed between adherence to the Mediterranean diet and vitality $(\beta=3.38 ; 95 \% C I=1.68-5.07)$, physical function $(\beta=2.13 ; 95 \% \mathrm{CI}=1.15-3.11)$ and general health $(\beta=2.84 ; 95 \% \mathrm{CI}=1.16-4.51)$. Likewise, Bonaccio et al. [53] showed that adherence to the Mediterranean diet was positively associated with dimensions of mental health (vitality, social function) and physical health (physical functioning, role limitations due to physical and general health), but not pain. Furthermore, Muñoz [54] included multiple confounders, but still found the same result-adherence to the Mediterranean diet was associated with higher levels of perceived health, both physically and mentally-.

The study by Ruano et al. [55] compared the quality of life in the Western diet (high consumption of fast food, red meat, and industrial pastry) with the Mediterranean
Diet. Values for vitality, mental health, physical functioning, bodily pain and general health were significantly better in the population with greater adherence to the Mediterranean Diet. Moreover, another study published by Ruano et al. [56], linked the consumption of fat to quality of life and showed a significant inverse association between consumption of saturated fatty acids and the mental dimensions (vitality, social functioning and emotional role) and physical function (physical role and general health). Therefore, our results are in line with previous studies-a greater adherence to the Mediterranean diet is associated with higher scores on the mental dimension in the quality of life questionnaire (SF-12)-.

The main limitation of this study is its cross-sectional design that prevents any causal relationship between quality of life and lifestyles to be analyzed. The design (crosssectional study) and the questionnaire used to evaluate the adherence to the MD do not allow to assess retrospectively adherence to this dietary pattern nor its temporal association with HRQL. Another limitation is that the quality of life questionnaire used was self-reported. However, this questionnaire has been previously used in studies of similar characteristics.

\section{Conclusion}

In people with intermediate cardiovascular risk, better food habits and greater adherence to the Mediterranean diet are associated with higher scores on the mental component of quality of life. Likewise, increased physical activity is related with positive scores on the physical function.

\section{Additional file}

Additional file 1: Table S1. Brief description of the components of the SF-12 questionnaire. (DOCX $12 \mathrm{~kb}$ )

\section{Acknowledgments}

We are grateful to all professionals participating in the MARK study. Lead author for this group: Rafel Ramos: Research Unit, Primary Health Care, Girona. Jordi Gol Institute for Primary Care Research (IDIAP Jordi Gol),

Catalonia, Spain. E-mail: rramos.girona.ics@gencat.net. Coordinating Center: Rafel Ramos, Ruth Martí, Dídac Parramon, Anna Ponjoan, Miquel Quesada, Maria Garcia-Gil, Martina Sidera and Lourdes Camós. Research Unit, Primary Health Care. Jordi Gol Institute for Primary Care Research (IDIAP Jordi Gol). C/ Maluquer Salvador, 11. 17002-Girona. Catalonia, Spain. Fernando Montesinos, Ignacio Montoya, Carlos López, Anna Agell, Núria Pagès of the Primary Care Services, Girona. Catalan Institute of Health (ICS), Catalonia, Spain. Irina Gil, Anna Maria Castro of the Primary Care Services, Girona. Institut d'Assistència Sanitaria (IAS), Catalonia, Spain. Fernando Rigo, Guillermo Frontera, Antònia Rotger, Natalia Feuerbach, Susana Pons, Natividad Garcia, John Guillaumet, Micaela Llull and Mercedes Gutierrez of the Health Center Primary Care San Agustín. Ibsalut Balears, Spain. Cristina Agudo-Conde, Leticia Gómez-Sanchez, Carmen Castaño-Sanchez, Carmela Rodriguez-Martín, Benigna Sanchez-

Salgado, Angela de Cabo-Laso, Marta Gómez-Sánchez, Emiliano RodriguezSanchez, Jose Angel Maderuelo-Fernandez, Emilio Ramos-Delgado, Carmen Patino-Alonso, Jose I Recio-Rodriguez, Manuel A Gomez-Marcos and Luis Garcia-Ortiz of the Primary Care Research Unit of the Alamedilla Health Center, Salamanca, Spain. Castilla and León Health Service-SACYL. 


\section{Funding}

This work was supported by grants funded by the Spanish Ministry of Science and Innovation (MICINN) and Carlos III Health Institute/European Regional Development Fund (ERDF) (MICINN, ISCIII/FEDER) (Red RedIAPPRD12/0005, Research Groups: RD12/0005/0004, RD12/0005/0002, RD12/0005/0011) and by the Health Research Fund (PI10/01088, PI10/02077, PI10/02043) and Regional Health Management of Castilla and Leon (GRS 635/A/11; GRS 906/B/14). Funder's had no role in the design, analysis or writing of this article.

\section{Availability of data and materia}

The dataset(s) supporting the conclusions of this article is (are) included within the article (and its additional file(s))

\section{Authors' contributions}

NSA prepared the manuscript draft, participated in fund raising, interpretation of results and corrected the final version of the manuscript. JIR participated in the study design, interpretation of results and manuscript review. JAM and LGO performed all analytical methods, interpretation of results, and manuscript review. RAD, CAC, CRM, BSS and ACL participated in data collection and manuscript review. MAM, JIR, RR and MAG participated in the protocol design, fund raising, analysis of results, and final review of the manuscript. Finally, all authors reviewed and approved the final version of the manuscript.

\section{Authors' information}

NSA: Primary Care Research Unit, The Alamedilla Health Center. Castilla and León Health Service (SACYL), Biomedical Research Institute of Salamanca (IBSAL), Salamanca, Spain.

RAD: Primary Care Research Unit, The Alamedilla Health Center. Castilla and León Health Service (SACYL), Biomedical Research Institute of Salamanca (IBSAL), Spanish Network for Preventive Activities and Health Promotion (redIAPP), Salamanca, Spain.

LGO: Primary Care Research Unit, The Alamedilla Health Center. Castilla and León Health Service (SACYL), Biomedical Research Institute of Salamanca (IBSAL), Spanish Network for Preventive Activities and Health Promotion (redIAPP), Biomedical and diagnostic sciences department, University of Salamanca, Salamanca, Spain.

CAC: Primary Care Research Unit, The Alamedilla Health Center. Castilla and León Health Service (SACYL), Biomedical Research Institute of Salamanca (IBSAL), Spanish Network for Preventive Activities and Health Promotion (redlAPP), Salamanca, Spain.

CRM: Primary Care Research Unit, The Alamedilla Health Center. Castilla and León Health Service (SACYL), Biomedical Research Institute of Salamanca (IBSAL), Spanish Network for Preventive Activities and Health Promotion (redIAPP), Salamanca, Spain.

ACL: Primary Care Research Unit, The Alamedilla Health Center. Castilla and León Health Service (SACYL), Biomedical Research Institute of Salamanca (IBSAL), Spanish Network for Preventive Activities and Health Promotion (redIAPP), Salamanca, Spain.

BSS: Primary Care Research Unit, The Alamedilla Health Center. Castilla and León Health Service (SACYL), Biomedical Research Institute of Salamanca (IBSAL), Spanish Network for Preventive Activities and Health Promotion (redIAPP), Salamanca, Spain.

RR: Research Unit Family Medicine, Girona. Jordi Gol Institute for Primary Care Research (IDIAP Jordi Gol), Translab Research Group. Medical Sciences department, School of Medicine, University of Girona, Girona Biomedical Research Institute (IDIBGI), Dr. Trueta University Hospital, Catalonia, Spain. JAM: Primary Care Research Unit, The Alamedilla Health Center. Castilla and León Health Service (SACYL), Biomedical Research Institute of Salamanca (IBSAL), Spanish Network for Preventive Activities and Health Promotion (redIAPP), Salamanca, Spain.

MAM: Primary Care Research Unit, The Alamedilla Health Center. Castilla and León Health Service (SACYL), Biomedical Research Institute of Salamanca (IBSAL), Spanish Network for Preventive Activities and Health Promotion (redIAPP), Medicine department, University of Salamanca, Salamanca, Spain. JIR: Primary Care Research Unit, The Alamedilla Health Center. Castilla and León Health Service (SACYL), Biomedical Research Institute of Salamanca (IBSAL), Spanish Network for Preventive Activities and Health Promotion (redIAPP), Salamanca, Spain.

\section{Competing interest}

The authors declare that they have no competing interests.

\section{Consent for publication}

Not applicable.

\section{Ethics approval and consent to participate}

This study was conducted according to the guidelines laid down in the Declaration of Helsinki and all procedures involving human individuals were approved by the Salamanca Hospital ethics committee. Written informed consent was obtained from all subjects.

\section{Author details}

'Primary Care Research Unit, The Alamedilla Health Center, Castilla and León Health Service (SACYL), Biomedical Research Institute of Salamanca (IBSAL), Spanish Network for Preventive Activities and Health Promotion (redIAPP), 37003 Salamanca, Spain. ${ }^{2}$ Department of Biomedical and Diagnostic Sciences, University of Salamanca, Salamanca, Spain. ${ }^{3}$ Research Unit Family Medicine, Girona. Jordi Gol Institute for Primary Care Research (IDIAP Jordi Gol), Translab Research Group. Medical Sciences Department, School of Medicine, University of Girona, Girona Biomedical Research Institute (IDIBGI), Dr. Trueta University Hospital, Catalonia, Spain. ${ }^{4}$ Department of Medicine, University of Salamanca, Salamanca, Spain. ${ }^{5}$ Department of Nursing and Physiotherapy, University of Salamanca, Salamanca, Spain.

\section{Received: 17 March 2016 Accepted: 1 December 2016}

\section{Published online: 07 December 2016}

\section{References}

1. Garratt A, Schmidt L, Mackintosh A, Fitzpatrick R. Quality of life measurement: bibliographic study of patient assessed health outcome measures. BMJ. 2002;324:1417.

2. Valderas JM, Alonso J. Patient reported outcome measures: a model-based classification system for research and clinical practice. Qual Life Res. 2008;17: 1125-35.

3. Schmidt S, Vilagut G, Garin O, Cunillera O, Tresserras R, Brugulat P, Mompart A, Medina A, Ferrer M, Alonso J. Reference guidelines for the 12-Item ShortForm Health Survey version 2 based on the Catalan general population. Med Clin (Barc). 2012:139:613-25.

4. Vilagut G, Valderas JM, Ferrer M, Garin O, Lopez-Garcia E, Alonso J. Interpretation of SF-36 and SF-12 questionnaires in Spain: physical and mental components. Med Clin (Barc). 2008;130:726-35.

5. Silvers KM, Scott KM. Fish consumption and self-reported physical and mental health status. Public Health Nutr. 2002:5:427-31.

6. Smith AP. The concept of well-being: relevance to nutrition research. Br J Nutr. 2005:93 Suppl 1:S1-5.

7. Myint PK, Welch AA, Bingham SA, Surtees PG, Wainwright NW, Luben RN, Wareham NJ, Smith RD, Harvey IM, Day NE, Khaw KT. Fruit and vegetable consumption and self-reported functional health in men and women in the European Prospective Investigation into Cancer-Norfolk (EPIC-Norfolk): a population-based cross-sectional study. Public Health Nutr. 2007:10:34-41.

8. Blank L, Grimsley M, Goyder E, Ellis E, Peters J. Community-based lifestyle interventions: changing behaviour and improving health. J Public Health (Oxf). 2007;29:236-45.

9. Myint PK, Welch AA, Bingham SA, Luben RN, Wareham NJ, Day NE, Khaw $K T$. Habitual fish consumption and risk of incident stroke: the European Prospective Investigation into Cancer (EPIC)-Norfolk prospective population study. Public Health Nutr. 2006:9:882-8.

10. Hislop TG, Bajdik CD, Balneaves LG, Holmes A, Chan S, Wu E, Abanto ZU, Butler AL. Physical and emotional health effects and social consequences after participation in a low-fat, high-carbohydrate dietary trial for more than 5 years. J Clin Oncol. 2006;24:2311-7.

11. Plaisted CS, Lin PH, Ard JD, McClure ML, Svetkey LP. The effects of dietary patterns on quality of life: a substudy of the Dietary Approaches to Stop Hypertension trial. J Am Diet Assoc. 1999;99:S84-9.

12. Trichopoulou A, Lagiou P. Healthy traditional Mediterranean diet: an expression of culture, history, and lifestyle. Nutr Rev. 1997:55:383-9.

13. Estruch R, Ros E, Salas-Salvado J, Covas MI, Corella D, Aros F, Gomez-Gracia E, Ruiz-Gutierrez V, Fiol M, Lapetra J, et al. Primary prevention of cardiovascular disease with a Mediterranean diet. N Engl J Med. 2013;368:1279-90.

14. Blair SN. Physical inactivity: the biggest public health problem of the $21 \mathrm{st}$ century. Br J Sports Med. 2009;43:1-2. 
15. Pedersen BK, Saltin B. Evidence for prescribing exercise as therapy in chronic disease. Scand J Med Sci Sports. 2006;16 Suppl 1:3-63.

16. Martin-Valero R, Cuesta-Vargas Al, Labajos-Manzanares MT. Effectiveness of the physical activity promotion programme on the quality of life and the cardiopulmonary function for inactive people: randomized controlled trial. BMC Public Health. 2013;13:127.

17. Kovacs E, Prokai L, Meszaros L, Gondos T. Adapted physical activity is beneficial on balance, functional mobility, quality of life and fall risk in community-dwelling older women: a randomized single-blinded controlled trial. Eur J Phys Rehabil Med. 2013;49:301-10.

18. Brown DW, Brown DR, Heath GW, Balluz L, Giles WH, Ford ES, Mokdad AH. Associations between physical activity dose and health-related quality of life. Med Sci Sports Exerc. 2004;36:890-6.

19. Vuillemin A, Boini S, Bertrais S, Tessier S, Oppert JM, Hercberg S, Guillemin F, Briancon S. Leisure time physical activity and health-related quality of life. Prev Med. 2005:41:562-9.

20. Koltyn KF. The association between physical activity and quality of life in older women. Womens Health Issues. 2001;11:471-80.

21. Stephens T. Physical activity and mental health in the United States and Canada: evidence from four population surveys. Prev Med. 1988;17:35-47.

22. Figueira HA, Fiqueira AA, Cader SA, Guimaraes AC, De Oliveira RJ, Fiqueira JA, Figueira OA, Dantas EH. Effects of a physical activity governmental health programme on the quality of life of elderly people. Scand J Public Health. 2012:40:418-22

23. Jepsen R, Aadland E, Andersen JR, Natvig GK. Associations between physical activity and quality of life outcomes in adults with severe obesity: a crosssectional study prior to the beginning of a lifestyle intervention. Health Qual Life Outcomes. 2013;11:187.

24. Marrugat J, Vila J, Baena-Diez JM, Grau M, Sala J, Ramos R, Subirana I, Fito M, Elosua R. Relative validity of the 10-year cardiovascular risk estimate in a population cohort of the REGICOR study. Rev Esp Cardiol. 2011:64:385-94.

25. Allen J, Inder KJ, Harris ML, Lewin TJ, Attia JR, Kelly BJ. Quality of life impact of cardiovascular and affective conditions among older residents from urban and rural communities. Health Qual Life Outcomes. 2013;11:140.

26. Piepoli MF, Hoes AW, Agewall S, Albus C, Brotons C, Catapano AL, Cooney MT, Corra U, Cosyns B, Deaton C, et al. 2016 European Guidelines on cardiovascular disease prevention in clinical practice: The Sixth Joint Task Force of the European Society of Cardiology and Other Societies on Cardiovascular Disease Prevention in Clinical Practice (constituted by representatives of 10 societies and by invited experts) Developed with the special contribution of the European Association for Cardiovascular Prevention \& Rehabilitation (EACPR). Eur Heart J. 2016:37:2315-81.

27. Cooney MT, Dudina A, Whincup P, Capewell S, Menotti A, Jousilahti P, Njolstad I, Oganov R, Thomsen T, Tverdal A, et al. Re-evaluating the Rose approach: comparative benefits of the population and high-risk preventive strategies. Eur J Cardiovasc Prev Rehabil. 2009;16:541-9.

28. Marti R, Parramon D, Garcia-Ortiz L, Rigo F, Gomez-Marcos MA, Sempere I, Garcia-Regalado N, Recio-Rodriquez JI, Agudo-Conde C, Feuerbach N, et al. Improving interMediAte risk management. MARK study. BMC CardiovasC Disord. 2011;11:61.

29. Marrugat J, D'Agostino R, Sullivan L, Elosua R, Wilson P, Ordovas J, Solanas P, Cordon F, Ramos R, Sala J, et al. An adaptation of the Framingham coronary heart disease risk function to European Mediterranean areas. J Epidemiol Community Health. 2003;57:634-8.

30. Conroy RM, Pyorala K, Fitzgerald AP, Sans S, Menotti A, De Backer G, De Bacquer D, Ducimetiere $P$, Jousilahti $P$, Keil $U$, et al. Estimation of ten-year risk of fatal cardiovascular disease in Europe: the SCORE project. Eur Heart J. 2003;24:987-1003

31. Mancia G, De Backer G, Dominiczak A, Cifkova R, Fagard R, Germano G, Grassi G, Heagerty AM, Kjeldsen SE, Laurent S, et al. Guidelines for the Management of Arterial Hypertension: The Task Force for the Management of Arterial Hypertension of the European Society of Hypertension (ESH) and of the European Society of Cardiology (ESC). J Hypertens. 2007;2007(25):1105-87.

32. Schroder H, Benitez Arciniega A, Soler C, Covas MI, Baena-Diez JM, Marrugat J. Validity of two short screeners for diet quality in time-limited settings. Public Health Nutr. 2012;15:618-26.

33. Martinez-Gonzalez MA, Fernandez-Jarne E, Serrano-Martinez M, Wright M, Gomez-Gracia E. Development of a short dietary intake questionnaire for the quantitative estimation of adherence to a cardioprotective Mediterranean diet. Eur J Clin Nutr. 2004;58:1550-2.
34. Elosua R, Marrugat J, Molina L, Pons S, Pujol E. Validation of the Minnesota Leisure Time Physical Activity Questionnaire in Spanish men. The MARATHOM investigators. Am J Epidemiol. 1994;139:1197-209.

35. Elosua R, Garcia M, Aguilar A, Molina L, Covas MI, Marrugat J. Validation of the Minnesota Leisure Time Physical Activity Questionnaire in Spanish Women. Investigators of the MARATDON group. Med Sci Sports Exerc. 2000;32:1431-7.

36. Ruiz Comellas A, Pera G, Baena Diez JM, Mundet Tuduri X, Alzamora Sas T, Elosua R, Toran Monserrat P, Heras A, Fores Raurell R, Fuste Gamisans M, Fabrega Camprubi M. Validation of a Spanish short version of the Minnesota Leisure Time Physical Activity Questionnaire (VREM). Rev Esp Salud Publica. 2012;86:495-508.

37. Andresen EM, Meyers AR. Health-related quality of life outcomes measures. Arch Phys Med Rehabil. 2000;81:S30-45.

38. Ware Jr J, Kosinski M, Keller SD. A 12-Item Short-Form Health Survey: construction of scales and preliminary tests of reliability and validity. Med Care. 1996:34:220-33.

39. Charlson ME, Pompei $P$, Ales $K L$, Mackenzie CR. A new method of classifying prognostic comorbidity in longitudinal studies: development and validation. J Chronic Dis. 1987;40:373-83.

40. O'Brien E, Asmar R, Beilin L, Imai Y, Mancia G, Mengden T, Myers M, Padfield P, Palatini P, Parati G, et al. Practice guidelines of the European Society of Hypertension for clinic, ambulatory and self blood pressure measurement. J Hypertens. 2005;23:697-701.

41. Heesch KC, van Gellecum YR, Burton NW, van Uffelen JG, Brown WJ. Physical activity and quality of life in older women with a history of depressive symptoms. Prev Med. 2016;91:299-305.

42. Perez-Tasigchana RF, Leon-Munoz LM, Lopez-Garcia E, Banegas JR, Rodriguez-Artalejo F, Guallar-Castillon P. Mediterranean Diet and healthrelated quality of life in two cohorts of community-dwelling older adults. PLoS One. 2016;11:e0151596.

43. Thiel DM, Al Sayah F, Vallance JK, Johnson ST, Johnson JA. Association between physical activity and health-related quality of life in adults with type 2 diabetes. Can J Diabetes. 2016. http://www.sciencedirect.com/ science/article/pii/S1499267116300910.

44. Vagetti GC, Barbosa Filho VC, Moreira NB, Oliveira V, Mazzardo O, Campos W. Association between physical activity and quality of life in the elderly: a systematic review, 2000-2012. Rev Bras Psiquiatr. 2014;36:76-88.

45. Cash SW, Duncan GE, Beresford SA, McTiernan A, Patrick DL. Increases in physical activity may affect quality of life differently in men and women: the PACE project. Qual Life Res. 2013;22:2381-8.

46. Hebestreit $\mathrm{H}$, Schmid K, Kieser S, Junge S, Ballmann M, Roth K, Hebestreit A, Schenk T, Schindler C, Posselt HG, Kriemler S. Quality of life is associated with physical activity and fitness in cystic fibrosis. BMC Pulm Med. 2014;14:26.

47. Waijers PM, Feskens EJ, Ocke MC. A critical review of predefined diet quality scores. Br J Nutr. 2007:97:219-31.

48. Tong TY, Wareham NJ, Khaw KT, Imamura F, Forouhi NG. Prospective association of the Mediterranean diet with cardiovascular disease incidence and mortality and its population impact in a non-Mediterranean population: the EPIC-Norfolk study. BMC Med. 2016;14:135.

49. Godos J, Zappala G, Bernardini S, Giambini I, Bes-Rastrollo M, MartinezGonzalez M. Adherence to the Mediterranean diet is inversely associated with metabolic syndrome occurrence: a meta-analysis of observational studies. Int J Food Sci Nutr. 2016:1-11. http://dx.doi.org/10.1080/09637486. 2016.1221900.

50. Petersson SD, Philippou E. Mediterranean diet, cognitive function, and dementia: a systematic review of the evidence. Adv Nutr. 2016;7:889-904.

51. Rosato V, Guercio V, Bosetti C, Negri E, Serraino D, Giacosa A, Montella M, La Vecchia C, Tavani A. Mediterranean diet and colorectal cancer risk: a pooled analysis of three Italian case-control studies. Br J Cancer. 2016;115:862-5.

52. Henriquez Sanchez P, Ruano C, de Irala J, Ruiz-Canela M, Martinez-Gonzalez MA, Sanchez-Villegas A. Adherence to the Mediterranean diet and quality of life in the SUN project. Eur J Clin Nutr. 2012;66:360-8.

53. Bonaccio M, Di Castelnuovo A, Bonanni A, Costanzo S, De Lucia F, Pounis G, Zito F, Donati MB, de Gaetano G, lacoviello L. Adherence to a Mediterranean diet is associated with a better health-related quality of life: a possible role of high dietary antioxidant content. BMJ Open. 2013;3: e003003.

54. Munoz MA, Fito M, Marrugat J, Covas MI, Schroder H. Adherence to the Mediterranean diet is associated with better mental and physical health Br J Nutr. 2009;101:1821-7. 
55. Ruano C, Henriquez P, Martinez-Gonzalez MA, Bes-Rastrollo M, Ruiz-Canela M, Sanchez-Villegas A. Empirically derived dietary patterns and healthrelated quality of life in the SUN project. PLoS One. 2013;8:e61490.

56. Ruano C, Henriquez P, Bes-Rastrollo M, Ruiz-Canela M, del Burgo CL, Sanchez-Villegas A. Dietary fat intake and quality of life: the SUN project. Nutr J. 2011;10:121.

Submit your next manuscript to BioMed Central and we will help you at every step:

- We accept pre-submission inquiries

- Our selector tool helps you to find the most relevant journal

- We provide round the clock customer support

- Convenient online submission

- Thorough peer review

- Inclusion in PubMed and all major indexing services

- Maximum visibility for your research

Submit your manuscript at www.biomedcentral.com/submit 